\title{
Platelet count is associated with sustained virological response rates in treatments for chronic hepatitis $\mathrm{C}$
}

\author{
Baek Gyu Jun ${ }^{1, \star}$, Eui Ju Park ${ }^{2, \star}$, Woong Cheul Lee ${ }^{2}$, Jae Young Jang ${ }^{2}$, Soung Won Jeong ${ }^{2}$, Young Don Kim², \\ Gab Jin Cheon ${ }^{1}$, Young Sin $\mathrm{Cho}^{3}$, Sae Hwan Lee ${ }^{3}$, Hong Soo Kim³ ${ }^{3}$ Yun Nah Lee ${ }^{4}$, Sang Gyune Kim${ }^{4}$, \\ Young Seok Kim ${ }^{4}$, and Boo Sung $\mathrm{Kim}^{2}$
}

\begin{abstract}
${ }^{1}$ Department of Internal Medicine, Gangneung Asan Hospital, University of Ulsan College of Medicine, Gangneung; ${ }^{2}$ Institute for Digestive Research, Digestive Disease Center, Department of Internal Medicine, Soonchunhyang University Seoul Hospital, Seoul; ${ }^{3}$ Institute for Digestive Research, Digestive Disease Center, Department of Internal Medicine, Soonchunhyang University Cheonan Hospital, Cheonan; ${ }^{4}$ Institute for Digestive Research, Digestive Disease Center, Department of Internal Medicine, Soonchunhyang University Bucheon Hospital, Bucheon, Korea
\end{abstract}

Received: September 21, 2017 Revised : November 10, 2017 Accepted: November 19, 2017

\section{Correspondence to} Jae Young Jang, M.D.

Institute for Digestive Research, Digestive Disease Center, Department of Internal Medicine, Soonchunhyang University Seoul Hospital, 59 Daesagwan-ro, Yongsan-gu, Seoul 04401, Korea

Tel: +82-2-709-9202

Fax: +82-2-709-9696

E-mail:jyjang@schmc.ac.kr

*These authors contributed equally to this work.
Background/Aims: This study was conducted to clarify the sustained virological response (SVR) prediction ability of baseline and treatment-related factors in patients with chronic hepatitis $\mathrm{C}$ virus (HCV) infection.

Methods: This retrospective study collected data at four tertiary referral hospitals between June 2004 and July 2012. Out of 476 patients, 330 treatment-naïve patients with chronic HCV infection were recruited. Pegylated interferon $\alpha-2 a /-$ $2 b$ plus ribavirin was administered for either 24 or 48 weeks depending on the HCV genotype. The baseline and treatment-related predictive factors of SVR were evaluated by analyzing data measured before treatment (i.e., baseline) and during treatment.

Results: SVR rates for genotypes 1 and 2 were 63\% (97/154) and 79.5\% (140/176), respectively $(p=0.001)$. Multivariate analysis for baseline factors revealed that young age $(p=0.009)$, genotype $2(p=0.001)$, HCV RNA level of $<800,000 \mathrm{IU} / \mathrm{mL}$ $(p<0.001)$, and a baseline platelet count of $>150 \times 10^{3} / \mu \mathrm{L}(p<0.001)$ were significant SVR predictors, regardless of the genotype. In particular, predictive accuracy for achievement of SVR was $87.3 \%$ for a baseline platelet count of $>150 \times 10^{3} / \mu \mathrm{L}$. In multivariate analysis for treatment-related factors, SVR was associated with achievement of a rapid virological response (RVR; $p<0.001$ ), treatment adherence of $\geq 80 / 80 / 80$ ( $p<0.001)$.

Conclusions: Young age, genotype 2, low HCV RNA level, RVR, and treatment adherence were significantly associated with SVR. In addition, platelet count was an independent predictive factor for SVR. Therefore, platelet count could be used to develop individualized treatment regimens and to optimize treatment outcomes in patients with chronic HCV infection.

Keywords: Hepatitis C, chronic; Sustained virological response; Blood platelets; Predictor 


\section{INTRODUCTION}

Chronic hepatitis C virus (HCV) infection is a major public health problem and is one of the main causes of serious liver disease worldwide [1-4]. Effective treatment for HCV infection is required to reduce the impact of this global health problem. The primary goal of administering antiviral agents, which eliminate detectable circulating HCV, is to cure the chronic HCV infection. The sustained virological response (SVR) has become an indication of curative therapy for chronic HCV infection, and is associated with both a histological improvement and a more favorable clinical outcome. Achieving an SVR is therefore an essential strategy in treating chronic HCV infection. However, the combination therapy of pegylated interferon (PEG-IFN) and ribavirin results in a SVR in only $40 \%$ to $50 \%$ of patients with HCV genotype 1 and in $70 \%$ to $80 \%$ of those with genotypes 2 or $3[5,6]$. In recent years, the directing antiviral agents (DAA) has improved cure rates of $80 \%$ to $100 \%$, but many patients are still not available DAA therapy because of high cost [7].

Factors that may influence the rate of response to therapy are being investigated extensively, and the results are awaited with great interest. Although the HCV genotype and HCV RNA level are known to be the strongest predictors of SVR, several other factors have also been found to affect treatment responses [8]. Various studies have shown that histological factors (including the amount of fibrosis) are traditional predictors of response, regardless of the genotype [9,10]. In addition, the platelet count has been suggested as a reliable standard for assessing fibrosis [11].

The aim of this study was to evaluate the SVR and to identify the predictive baseline (pretreatment) factors and treatment-related factors associated with SVR in treatment-naïve patients with chronic HCV infection treated with the combination of PEG-IFN $\alpha-2 a /-2 b$ and ribavirin, especially in Asian country.

\section{METHODS}

\section{Patients}

This retrospective, multicenter study collected data at four tertiary referral hospitals (Soonchunhyang University Seoul, Bucheon, Cheonan Hospital, and Gangneung
Asan Hospital) between June 2004 and July 2012. The following exclusion criteria were applied: (1) previous treatment for chronic HCV infection, (2) undergone hemodialysis, (3) presence of acute hepatitis, (4) unknown HCV genotype, (5) presence of hepatitis B virus co-infection, and (6) inadequate initial data. Of the 476 consecutive adult patients, 330 treatment-naive patients with chronic HCV infection were enrolled. This was a retrospective study without intervention or requirement for clinical specimens, and all of the data were analyzed anonymously, which meant that informed consent did not need to be obtained from the patients. The waiving of informed consent was approved by the Institutional Review Board (2009-04-012) at each participating center.

\section{Treatment for chronic HCV infection}

PEG-IFN $\alpha-2 a /-2 b$ plus ribavirin was administered for either 24 or 48 weeks depending on the HCV genotype. All patients were treated using standard protocols described in clinical practice guidelines, with either PEGIFN $\alpha$-2a (PEGASYS, Roche, Basel, Switzerland) or PEGIFN $\alpha-2 b$ (PEG-Intron, Schering-Plough, Kenilworth, NJ, USA) combined with ribavirin (Viramid, Ilsung Pharmaceuticals, Seoul, Korea). The patients were informed regarding the dosage of each drug and the treatment duration.

\section{Measurement of clinical data and laboratory profiles}

The diagnosis of cirrhosis was based on histology observations or clinical manifestations, laboratory data, and compatible abdominal imaging criteria. The laboratory data were evaluated according to treatment time for chronic HCV infection. The baseline laboratory results were assessed for the pretreatment (i.e., baseline) time point. During antiviral treatment, the HCV RNA levels were measured at baseline, and then at 4, 12, and 24 weeks after the end of the treatment. A baseline serum HCV RNA level of < 800,000 IU/mL was classified as low-level viremia. The HCV RNA level was measured using real-time polymerase chain reaction (Cobas AmpliPrep/Cobas TaqMan HCV test version 2.0, Roche Diagnostics, Basel, Switzerland; or Abbott Real Time HCV test, Abbott Diagnostics, Abbott Park, IL, USA). HCV genotyping was carried out via sequencing using a genetic analyzer (ABI 3130XL, Applied Biosystems, Hitachi, Tokyo, Japan). Information including treatment duration, 
dosage modification, and adherence to treatment were also assessed at the treatment cessation.

\section{Evaluation of efficacy and adherence to treatment}

Rapid virological response (RVR) and early virological response (EVR) were evaluated at 4, 12 weeks, respectively. Treatment for all HCV genotypes was stopped at week 12 if the HCV RNA decrease was less than $2 \log _{10} I U / \mathrm{mL}$, which was in accordance with the guidelines $[5,6]$. The efficacy of treatment was assessed using the SVR rate, which was defined as undetectable serum HCV RNA at 24 weeks after the end of treatment, with a target of $\geq$ $80 \%$ adherence to treatment duration, PEG-IFN $\alpha$-2a/$2 \mathrm{~b}$ dosage, and ribavirin dosage. Therefore, a treatment adherence of $\geq 80 / 80 / 80$ was defined as adhering to at least $80 \%$ of the scheduled interferon, ribavirin dosage and assigned treatment duration [12].

\section{Statistical analysis}

All treatment evaluations were assessed by intention-to-treat analysis. Patients who could not be judged as having achieved an SVR were considered non-SVR. Data are expressed as mean \pm SD or number (\%) values, as appropriate. When comparing the characteristics of patients in two different groups, the chi-square test and Fisher exact test were used for categorical data, and Student $t$ test and Mann-Whitney $U$ test were used for continuous variables. The results of the logistic regression analysis are reported as the odds ratio (OR) and 95\% confidence interval (CI). A receiver operating characteristic (ROC) curve was generated for the variables that were statistically significant in multivariate analysis to assess the predictive accuracy of these models and to determine the optimal cutoff points for predicting the achievement of SVR. Area under the receiver operating characteristic curve (AUC) analysis was conducted to determine the discriminatory ability of the data. For all statistical tests, $p<0.05$ was considered statistically significant. Data were analyzed statistically using SPSS version 17.0 for Windows (SPSS Inc., Chicago, IL, USA).

\section{RESULTS}

\section{Baseline characteristics}

The patients' baseline characteristics are given in Ta- ble 1. A total of 330 patients ( 176 men, 154 women; median age, 49 years) who were treated with the combination of PEG-IFN $\alpha-2 \mathrm{a} /-2 \mathrm{~b}$ and ribavirin were investigated in this study. Of these, 154 and 176 patients had genotypes 1 and 2, respectively. The serum HCV RNA level was 3.20 $\pm 1.56 \times 10^{6} \mathrm{IU} / \mathrm{mL}$, and $53.3 \%$ (176/330) of the patients had HCV RNA levels of $<800,000 \mathrm{IU} / \mathrm{mL}$. The proportions of patients with an adherence of $\geq 80 / 80 / 80$ and treatment duration of $\geq 80 \%$ were $65.7 \%$ and $83.0 \%$, respectively;

Table 1. Baseline clinical characteristics $(n=330)$

\begin{tabular}{|c|c|}
\hline Characteristic & Value \\
\hline Male sex & $176(53 \cdot 3)$ \\
\hline Age, yr & $49(18-72)$ \\
\hline Cirrhosis & $29(8.7)$ \\
\hline Diabetes mellitus & $56(17)$ \\
\hline BMI, $\mathrm{kg} / \mathrm{m}^{2}$ & $24(16-33)$ \\
\hline $\mathrm{BMI} \geq 25 \mathrm{~kg} / \mathrm{m}^{2}$ & $119(36.1)$ \\
\hline PEG-IFN $\alpha-2 a / P E G-I N F ~ \alpha-2 b$ & $143(33.3) / 187(56.7)$ \\
\hline Genotype $1 /$ Genotype 2 & $154(46.7) / 176(53.3)$ \\
\hline HCV RNA, $\log _{10} \mathrm{IU} / \mathrm{mL}$ & $5.75 \pm 0.92$ \\
\hline HCV RNA < 800,000 IU/mL & $176(53 \cdot 3)$ \\
\hline Achievement of RVR ( $\mathrm{n}=247)$ & $183(55 \cdot 5)$ \\
\hline Achievement of EVR $(n=267)$ & $248(75.2)$ \\
\hline Achievement of SVR & $237(71.8)$ \\
\hline Treatment duration of $\geq 80 \%$ & $274(83.0)$ \\
\hline PEG-IFN dosage of $\geq 80 \%$ & $266(80.6)$ \\
\hline Ribavirin dosage of $\geq 80 \%$ & $275(83 \cdot 3)$ \\
\hline Treatment adherence of $\geq 80 / 80 / 80$ & $217(65.7)$ \\
\hline $\mathrm{WBC}, / \mu \mathrm{L}$ & $5,005(1,800-13,620)$ \\
\hline Hemoglobin, g/dL & $13.7(10-17.7)$ \\
\hline Platelet, $\times 10^{3} / \mu \mathrm{L}$ & $173(80-404)$ \\
\hline ALT, U/L & $54(7-1,190)$ \\
\hline Total bilirubin, mg/dL & $0.69(0.2-3.7)$ \\
\hline Cholesterol, mg/dL (n = 345) & $150(90-347)$ \\
\hline GGT, U/L $(\mathrm{n}=328)$ & $50(8-245)$ \\
\hline Fasting glucose, mg/dL & $98(66-354)$ \\
\hline
\end{tabular}

Values are presented as number (\%), median (range), or mean \pm SD.

BMI, body mass index; PEG-IFN, pegylated interferon; HCV, hepatitis C virus; RVR, rapid virological response; EVR, early virological response; SVR, sustained virological response; WBC, white blood cell; ALT, alanine aminotransferase; GGT, gamma-glutamyltransferase. 
the corresponding values for patients who received $\geq$ $80 \%$ of the PEG-IFN $\alpha-2 \mathrm{a} /-2 \mathrm{~b}$ and ribavirin dosages for the scheduled treatment were $80.6 \%$ and $83.3 \%$.

\section{SVR to treatment}

An SVR was achieved in 237 (71.8\%) of the 330 treatment patients (Table 1). SVR rates for genotypes 1 and 2 were 63\% (97/154) and 79.5\% (140/176), respectively, by intention-to-treat analysis $(p=0.001)$. Although the SVR rate was significantly higher for genotype 1 than genotype 2 for the intention-to-treat analysis, there was no significant difference for the per-protocol analysis (74.7\% vs. $84.4 \%, p=0.087)$.

\section{Predictive factors of SVR at baseline}

Baseline factors that could be associated with an SVR were compared between SVR and non-SVR patients (Table 2). Univariate analysis revealed that the following factors could be significantly associated with SVR: age, HCV genotype, HCV RNA level (<800,000 IU/mL), and baseline platelet count. Multivariate analysis of these significant baseline factors revealed that young age (OR, 1.037; $95 \% \mathrm{CI}$, 1.009 to $1.066 ; p=0.009)$, genotype $2(\mathrm{OR}$, 2.620; $95 \%$ CI, 1.482 to $4.633 ; p=0.001)$, HCV RNA level of < 800,000 IU/mL (OR, 2.857; 95\% CI, 1.610 to 5.050; $p<$ 0.001 ), and baseline platelet count of $>150 \times 10^{3} / \mu \mathrm{L}$ (OR, 1.020; $95 \%$ CI, 1.013 to 1.027 ; $p<0.001$ ) were significant-

Table 2. Predictive factors of SVR at baseline

\begin{tabular}{|c|c|c|c|c|c|}
\hline Variable & $\operatorname{SVR}(\mathrm{n}=237)$ & Non-SVR $(n=93)$ & OR & $95 \% \mathrm{CI}$ & $p$ value \\
\hline \multicolumn{6}{|l|}{ Univariate analysis } \\
\hline Male sex & $126(53.2)$ & $50(53.8)$ & 0.976 & $0.604-1.576$ & 0.922 \\
\hline Age, yr & $47 \pm 12$ & $53 \pm 11$ & 0.958 & $0.936-0.979$ & $<0.001$ \\
\hline Cirrhosis & $20(8.4)$ & $9(9.7)$ & 0.907 & $0.399-2.061$ & 0.140 \\
\hline Diabetes mellitus & $35(14.8)$ & $21(22.6)$ & 1.683 & $0.920-3.080$ & 0.091 \\
\hline $\mathrm{BMI} \geq 25 \mathrm{~kg} / \mathrm{m}^{2}$ & $91(40.8)$ & $36(40.4)$ & 1.015 & $0.615-1.674$ & 0.954 \\
\hline PEG-IFN $\alpha-2 \mathrm{a}$ & $105(73 \cdot 4)$ & $38(26.6)$ & 1.151 & $0.708-1.873$ & 0.570 \\
\hline PEG-IFN $\alpha-2 b$ & $132(70.6)$ & $55(29.4)$ & & & \\
\hline Genotype 1 & $97(63)$ & $57(37)$ & 2.285 & $1.399-3.734$ & 0.001 \\
\hline Genotype 2 & $140(79 \cdot 5)$ & $36(20.5)$ & & & \\
\hline HCV RNA of $<800,000 \mathrm{IU} / \mathrm{mL}$ & $143(60.3)$ & $33(35 \cdot 5)$ & 2.762 & $1.681-4.545$ & $<0.001$ \\
\hline $\mathrm{WBC}, \times 10^{3} / \mu \mathrm{L}$ & $5,110(1,800-10,300)$ & $4,900(1,980-13,620)$ & 1.000 & $1.000-1.000$ & 0.842 \\
\hline Hemoglobin, g/dL & $13.6(10-17.7)$ & $13.8(10.1-17.4)$ & 1.051 & $0.900-1.228$ & 0.530 \\
\hline Platelet, $\times 10^{3} / \mu \mathrm{L}$ & $184(101-404)$ & $120(80-313)$ & 1.021 & $1.015-1.028$ & $<0.001$ \\
\hline ALT, U/L & $57(7-1,190)$ & $50(11-350)$ & 1.002 & $0.999-1.005$ & 0.182 \\
\hline Total bilirubin, mg/dL & $0.7(0.2-3.7)$ & $0.7(0.2-2.1)$ & 0.860 & $0.644-1.149$ & 0.307 \\
\hline Cholesterol, mg/dL & $152(90-347)$ & $149(91-243)$ & 1.002 & $0.994-1.011$ & 0.594 \\
\hline GGT, U/L & $48(8-245)$ & $60(11-218)$ & 0.996 & $0.991-1.001$ & 0.114 \\
\hline Fasting glucose, mg/dL & $108(66-354)$ & $103(71-297)$ & 0.994 & $0.989-1.000$ & 0.067 \\
\hline \multicolumn{6}{|l|}{ Multivariate analysis } \\
\hline Young age & & & 1.037 & $1.009-1.066$ & 0.009 \\
\hline Genotype 2 & & & 2.620 & $1.482-4.633$ & 0.001 \\
\hline HCV RNA of $<800,000 \mathrm{IU} / \mathrm{mL}$ & & & 2.857 & $1.610-5.050$ & $<0.001$ \\
\hline High baseline platelet count & & & 1.020 & $1.013-1.027$ & $<0.001$ \\
\hline
\end{tabular}

Values are presented as number (\%), mean $\pm \mathrm{SD}$, or median (range). OR by logistic regression analysis with backward elimination method.

SVR, sustained virological response; OR, odds ratio; CI, confidential interval; BMI, body mass index; PEG-IFN, pegylated interferon; HCV, hepatitis C virus; WBC, white blood cell; ALT, alanine aminotransferase; GGT, gamma-glutamyltransferase. 
ly associated with achievement of SVR, independent of other factors.

\section{Predictive factors of SVR during treatment}

Table 3 lists the results for the analysis of predictive factors of SVR related to the treatment. Of patients who achieved RVR and EVR, SVR was achieved by $82 \%$ (150/183) and 75.3\% (186/248), respectively. Achievement of RVR (OR, 3.984; 95\% CI, 2.020 to $7.874 ; p<0.001)$, treatment adherence of $\geq 80 / 80 / 80$ (OR, 4.058; 95\% CI, 2.103 to $7.832 ; p<0.001)$ were independently associated with SVR by multivariate analysis.

\section{Predictive factors of SVR according to genotype}

Table 4 lists the results for the multivariate analysis of SVR predictors according to genotype. In 154 patients

Table 3. Predictive factors of SVR during treatment

\begin{tabular}{|c|c|c|c|c|c|}
\hline Variable & $\operatorname{SVR}(n=237)$ & Non-SVR $(n=93)$ & OR & $95 \% \mathrm{CI}$ & $p$ value \\
\hline \multicolumn{6}{|l|}{ Univariate analysis } \\
\hline \multicolumn{6}{|l|}{$\operatorname{RVR}(\mathrm{n}=247)$} \\
\hline Yes & $150(82)$ & $33(18)$ & $4 \cdot 545$ & $2.451-8.403$ & $<0.001$ \\
\hline No & $32(50)$ & $32(50)$ & & & \\
\hline \multicolumn{6}{|l|}{$\operatorname{EVR}(n=267)$} \\
\hline Yes & $186(75 \cdot 3)$ & $62(24.7)$ & & & NA \\
\hline No & o & $19(100)$ & & & \\
\hline Treatment duration & $32.3 \pm 11.8$ & $32.2 \pm 17.9$ & 1.001 & $0.983-1.018$ & 0.951 \\
\hline Treatment adherence of $\geq 80 / 80 / 80$ & $174(73.4)$ & $43(46.2)$ & 3.212 & $1.949-5.291$ & $<0.001$ \\
\hline \multicolumn{6}{|l|}{ Multivariate analysis } \\
\hline Achievement of RVR & & & $3 \cdot 984$ & $2.020-7.874$ & $<0.001$ \\
\hline Treatment adherence of $\geq 80 / 80 / 80$ & & & 4.058 & $2.103-7.832$ & $<0.001$ \\
\hline
\end{tabular}

Values are presented as number (\%) or mean \pm SD. OR by logistic regression analysis with backward elimination method. SVR, sustained virological response; OR, odds ratio; CI, confidential interval; RVR, rapid virological response; EVR, early virological response; NA, not available.

Table 4. Predictive factors of SVR according to genotype (multivariate analysis)

\begin{tabular}{|c|c|c|c|c|c|}
\hline Variable & SVR & Non-SVR & OR & $95 \% \mathrm{CI}$ & $p$ value \\
\hline Genotype $1(n=154)$ & 97 & 57 & & & \\
\hline Young age & $44 \pm 11$ & $54 \pm 12$ & 1.058 & $1.021-1.098$ & 0.002 \\
\hline Baseline platelet count of $>150 \times 10^{3} / \mu \mathrm{L}$ & $192(101-386)$ & $117(85-192)$ & 1.020 & $1.011-1.030$ & $<0.001$ \\
\hline Achievement of $\operatorname{RVR}(\mathrm{n}=117)$ & $52 / 76(68.4)$ & $15 / 41(36.6)$ & 2.890 & $1.170-7.143$ & 0.022 \\
\hline Treatment adherence of $\geq 80 / 8 \mathrm{o} / 80$ & $71(73.2)$ & $24(42.1)$ & $4 \cdot 349$ & $1.764-10.722$ & 0.001 \\
\hline Genotype $2(n=176)$ & 140 & 36 & & & \\
\hline High baseline platelet count & $180(101-404)$ & $120(80-313)$ & 1.026 & $1.011-1.040$ & $<0.001$ \\
\hline HCV RNA of $<800,000 \mathrm{IU} / \mathrm{mL}$ & $95(67.9)$ & $10(27.8)$ & 7.092 & $2.299-21.739$ & 0.001 \\
\hline Achievement of RVR $(n=130)$ & $98 / 106(92.5)$ & $18 / 24(75)$ & 0.372 & $0.086-1.604$ & NS \\
\hline Treatment adherence of $\geq 80 / 80 / 80$ & $103(73.6)$ & $19(52.8)$ & 3.422 & $1.115-10.502$ & 0.032 \\
\hline
\end{tabular}

Values are presented as mean $\pm \mathrm{SD}$, median (range), or number (\%). OR by logistic regression analysis with backward elimination method.

SVR, sustained virological response; OR, odds ratio; CI, confidential interval; RVR, rapid virological response; HCV, hepatitis C virus; NS, not significance. 
with genotype 1, young age (OR, 1.058; 95\% CI, 1.021 to 1.098; $p=0.002)$, baseline platelet count of $>150 \times 10^{3} / \mu \mathrm{L}$ (OR, 1.020; 95\% CI, 1.011 to 1.030; $p<0.001$ ), achievement of RVR (OR, 2.890; 95\% CI, 1.1740 to $7.143 ; p=0.022$ ), and treatment adherence of $\geq 80 / 80 / 80$ (OR, 4.349; 95\% CI, 1.764 to $10.722 ; p=0.001$ ) were independently associated with SVR. In 176 patients with genotype 2, baseline platelet count of $>150 \times 10^{3} / \mu \mathrm{L}(\mathrm{OR}, 1.026 ; 95 \% \mathrm{CI}, 1.011$ to 1.040; $p<0.001)$, HCV RNA level of < 800,000 IU/mL (OR, 7.092; 95\% CI, 2.299 to 21.739; $p=0.001$ ), treatment adherence of $\geq 80 / 80 / 80$ (OR, 3.422; 95\% CI, 1.115 to 10.502; $p=0.032)$ were independently associated with SVR.

\section{Relationship between baseline platelet count and SVR}

The significance of baseline platelet count on SVR rate was evaluated. ROC curves were constructed to determine the optimal cutoff points of platelet count for prediction of SVR. A baseline platelet count of $>150 \times$ $10^{3} / \mu \mathrm{L}$ count at baseline was a potential predictive factor for SVR in entire patients with chronic HCV infection: a baseline platelet count of $>150 \times 10^{3} / \mu \mathrm{L}$ had a sensitivity of $76.0 \%$, a specificity of $83.9 \%$, and an AUC of 0.873 (Fig. 1A). In patients with genotype 1 and 2, a baseline platelet count of $>150 \times 10^{3} / \mu \mathrm{L}$ had a sensitivity of $83.5 \%$ and $77.2 \%$, a specificity of $77.2 \%$ and $80.7 \%$, and an AUC of 0.782 and 0.868 , respectively (Fig. $1 \mathrm{~B}$ and ${ }_{1} \mathrm{C}$ ).

\section{DISCUSSION}

This study investigated the factors that may contribute to an SVR in treatment-naive patients with chronic HCV infection who are treated with the combination of PEG-IFN $\alpha-2 \mathrm{a} /-2 \mathrm{~b}$ and ribavirin. Since baseline predictors of response are useful for advising patients about their likelihood of an SVR, and treatment-related predictors are useful for determining the treatment course and duration, factors that may influence the rate of an SVR to therapy have been investigated extensively [8]. The present study therefore focused on the SVR predictive ability of both baseline factors and treatment-related factors. Several predictors have been identified in previous clinical trials, of which the HCV genotype and HCV RNA levels have been considered the most important [5,8,13-15].

In the current study, the baseline (i.e., pretreatment) predictive factors of SVR were young age, genotype 2, HCV RNA level of $<800,000 \mathrm{IU} / \mathrm{mL}$, and a baseline platelet count of $>150 \times 10^{3} / \mu \mathrm{L}$. Similar to previous studies $[15,16]$, the SVR rate for antiviral therapy was higher in younger patients than in older patients in the present study. As mentioned above, HCV genotype is one of the most important SVR predictors. Consistent with previous studies, we found that the SVR rate was higher in genotype 2 patients than in genotype 1 patients, by intention-to-treat analysis ( $63 \%$ vs. $79.5 \%, p=0.001$ ).
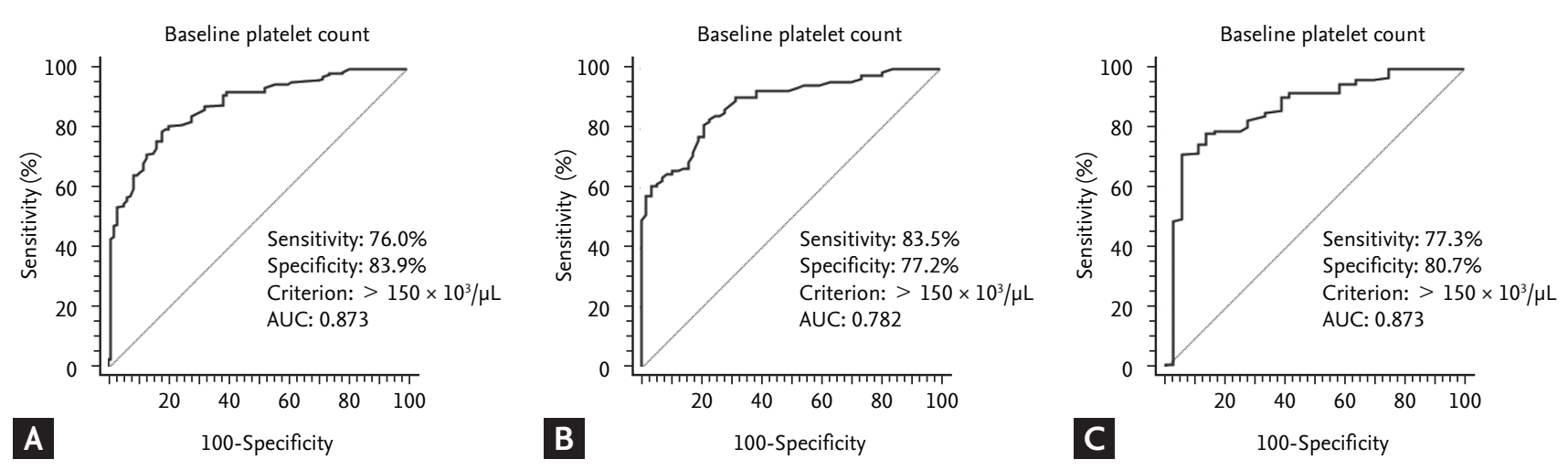

Figure 1. Receiver operating characteristic (ROC) curves were constructed to determine the optimal platelet-count cutoff points for the prediction of sustained virological response (SVR). (A) At baseline (i.e., pretreatment), a platelet count of $>150 \times 10^{3} / \mu \mathrm{L}$ could be a predictive factor related to the SVR in entire patient with hepatitis C virus infection (area under the receiver operating characteristic curve $[\mathrm{AUC}]=0.873$ ). (B) In patients with genotype 1 , a platelet count of $>150 \times 10^{3} / \mu \mathrm{L}$ could be a predictive factor related to the SVR (AUC = 0.782). (C) In patients with genotype 2, a platelet count of $>150 \times 10^{3} / \mu \mathrm{L}$ could be a predictive factor related to the SVR (AUC = 0.868). The solid line represents the ROC based on chance alone and has a c-statistic value of 0.5 . 
Interestingly, the SVR rates of both genotypes 1 and 2 in this study were higher than those reported previously $[5,15,17]$. However, the high SVR rate reported herein is compatible with the findings of previous Korean studies [18-20]. Although the reasons for this difference are largely unknown, the good outcomes of Eastern (including Korean) patients regarding treatment efficacy could be due to the favorable interleukin $28 \mathrm{~B}(I L-2 S)$ gene polymorphism [21,22], the lower proportion of obese patients, and greater treatment adherence [12,19,20]. Another possible reason for the present outcome could be the low number of cirrhotic patients and the $>60 \%$ high rate of a treatment adherence of $\geq 80 / 80 / 80$. In particular, the treatment was maintained for a sufficient period of time in $83 \%$ of patients. In the current study, adherence to treatment was an independent predictive factor for achievement of SVR, and the SVR rates of genotypes 1 and 2 patients were as high as $74.7 \%$ and $84.4 \%$, respectively, when a per-protocol analysis was applied. It is well known that improved adherence to treatment can enhance SVR rates $[12,18,23]$. Therefore, the present findings suggest that efforts to improve adherence to treatment could increase the SVR rate among patients who obtain better outcomes on antiviral therapy.

A low baseline HCV RNA level is associated with a significantly higher probability of achieving SVR. Our results did confirm the importance of baseline HCV RNA levels $(<800,000 \mathrm{IU} / \mathrm{mL})$ for achieving SVR by multivariate analysis $[8,15]$.

While baseline predictive factors of SVR are useful for predicting the efficacy of antiviral therapy, they are not sufficient for clinical decision making. Therefore, knowledge of predictive factors during treatment would be extremely valuable. This study found that achievement of RVR and a treatment adherence of $\geq 80 / 80 / 80$ were related to treatment-related predictive factors of SVR. This is consistent with it previously being shown that RVR at 4 weeks is an excellent predictor of SVR, especially in genotype $1[24,25]$. EVR, which is known to be one of the most important predictors of SVR, could not perform in regression analysis [26]. It would be impossible to analyses it as a predictive factor of SVR, because treatment was stopped in patients without EVR in accordance with the guidelines.

Another interesting finding of the present study is the association between platelet count and SVR in treatment for chronic HCV infection. It is well known that thrombocytopenia is associated with chronic HCV infection and could be significantly correlated with liver fibrosis stage $[11,27]$. In patients with chronic HCV infection, advanced fibrosis tends to be associated with a lower platelet count, and a decreased platelet count is in turn known to be associated with a diminished treatment response $[28,29]$. Mild thrombocytopenia is generally defined as a platelet count of $\leq 150 \times 10^{3} / \mu \mathrm{L}$, and a platelet count of $<100 \times 10^{3} / \mu \mathrm{L}$ has been used to identify liver cirrhosis in patients with chronic viral hepatitis $[11,30]$. In the present study, the rate of liver cirrhosis did not differ significantly between SVR and non-SVR patients. Nevertheless, a baseline platelet count of $>150 \times 10^{3} / \mu \mathrm{L}$ was identified as a predictive factor for SVR in entire patients with chronic HCV infection. This suggests that even in the absence of definitive evidence of liver cirrhosis based on clinical measurements, a platelet count of $\leq 150 \times 10^{3} / \mu \mathrm{L}$ is associated with advanced fibrosis in patients with chronic HCV infection. In agreement with this result, it has been reported that patients with a baseline platelet count of $>120 \times 10^{3} / \mu \mathrm{L}$ had a higher probability of an SVR [31-33]. Thus, the findings of the present study suggest that thrombocytopenia is an important factor for SVR prediction; it is considered beneficial in predicting the response of patients treated with PEGIFN plus ribavirin.

Treatment in patients with chronic HCV infection is changing from interferon based therapy to DAA. However, although DAA has high cure rate, many patients are not treated with DAA for cost and insurance problems [7]. Therefore, patients who have good baseline predictors such as a baseline platelet count of $>150 \times 10^{3} /$ $\mu \mathrm{L}$, young age, genotype 2 and low HCV RNA level can be treated with interferon based therapy instead of DAA.

This study was subject to several potential limitations. Selection bias was present due to the retrospective study design, and the unavailability of some data in the current study may have affected the results of the multivariate analysis. Despite these concerns, this study makes an important contribution to the understanding of predictive factors of SVR. Deviations from intention-to-treat analysis could introduce potential investigator bias with respect to interpretation of the results. This study did not investigate the IL-28 gene polymorphism. About $95 \%$ of Korean patients with chronic HCV infection have fa- 
vorable IL-2 $\delta$ gene polymorphism to virologic response. Therefore, guidelines of the Korean Association for the Study of the Liver did not recommend the evaluation of IL-2S gene polymorphism for prediction of SVR. Finally, it was possible to underestimate the degree of fibrosis and cirrhosis, because a liver biopsy or indirect fibrosis diagnosis method such as fibroscan were not performed in all of the patients. To overcome this limitation, liver cirrhosis was diagnosed in accordance with criteria based on clinical guidelines. The possibility of cirrhosis may be suggested by the history, clinical manifestation, histology, or compatible laboratory and imaging criteria.

In conclusion, young age, genotype 2, low HCV RNA level, RVR, and treatment adherence were significantly associated with SVR. Another finding of this study demonstrates that platelet count appears to be a significant factor predicting a greater likelihood of SVR, and could thus be a useful predictor for SVR. Platelet count might therefore be useful for developing individualized treatments and optimizing treatment outcomes in patients with chronic HCV infection. Further studies are needed to confirm this.

\section{KEY MESSAGE}

1. Platelet count appears to be a significant factor predicting sustained virological response (SVR).

2. A baseline platelet count of $>150 \times 10^{3} / \mu \mathrm{L}$ was identified as a predictive factor for SVR.

\section{Conflict of interest}

No potential conflict of interest relevant to this article was reported.

\section{Acknowledgments}

This work was supported by the Soonchunhyang University Research Fund.

\section{REFERENCES}

1. Lavanchy D. The global burden of hepatitis C. Liver Int 2009;29 Suppl 1:74-81.

2. Di Bisceglie AM. Hepatitis C and hepatocellular carcinoma. Hepatology 1997;26(3 Suppl 1):34S-38S.
3. Suh DJ, Jeong SH. Current status of hepatitis C virus infection in Korea. Intervirology 2006;49:70-75.

4. Kim BK, Jang ES, Kim JH, et al. Current status of and strategies for hepatitis C control in South Korea. Clin Mol Hepatol 2017;23:212-218.

5. European Association for the Study of the Liver. EASL Clinical Practice Guidelines: management of hepatitis C virus infection. J Hepatol 2011;55:245-264.

6. Ghany MG, Strader DB, Thomas DL, Seeff LB; American Association for the Study of Liver Diseases. Diagnosis, management, and treatment of hepatitis C: an update. Hepatology 2009;49:1335-1374.

7. Bickerstaff $\mathrm{C}$. The cost-effectiveness of novel direct acting antiviral agent therapies for the treatment of chronic hepatitis C. Expert Rev Pharmacoecon Outcomes Res 2015;15:787-800.

8. Rosen HR. Clinical practice. Chronic hepatitis C infection. N Engl J Med 2011;364:2429-2438.

9. Thompson AJ, Muir AJ, Sulkowski MS, et al. Interleukin-28B polymorphism improves viral kinetics and is the strongest pretreatment predictor of sustained virologic response in genotype 1 hepatitis $\mathrm{C}$ virus. Gastroenterology 2010;139:120-129.

10. Kamal SM, Nasser IA. Hepatitis C genotype 4: what we know and what we don't yet know. Hepatology 2008;47:13711383.

11. Olariu M, Olariu C, Olteanu D. Thrombocytopenia in chronic hepatitis C. J Gastrointestin Liver Dis 2010;19:381385 .

12. McHutchison JG, Manns M, Patel K, et al. Adherence to combination therapy enhances sustained response in genotype-1-infected patients with chronic hepatitis $\mathrm{C}$. Gastroenterology 2002;123:1061-1069.

13. Fried MW, Shiffman ML, Reddy KR, et al. Peginterferon alfa-2a plus ribavirin for chronic hepatitis $\mathrm{C}$ virus infection. N Engl J Med 2002;347:975-982.

14. Hadziyannis SJ, Sette H Jr, Morgan TR, et al. Peginterferon-alphaza and ribavirin combination therapy in chronic hepatitis C: a randomized study of treatment duration and ribavirin dose. Ann Intern Med 2004;140:346-355.

15. Lee SS, Abdo AA. Predicting antiviral treatment response in chronic hepatitis C: how accurate and how soon? J Antimicrob Chemother 2003;51:487-491.

16. Idrees M, Riazuddin S. A study of best positive predictors for sustained virologic response to interferon alpha plus ribavirin therapy in naive chronic hepatitis $\mathrm{C}$ patients. 
BMC Gastroenterol 2009;9:5.

17. Locarnini SA. Clinical relevance of viral dynamics and genotypes in hepatitis B virus. J Gastroenterol Hepatol 2002;17 Suppl 3:S322-S328.

18. Heo NY, Lim YS, Lee HC, et al. High effectiveness of peginterferon alfa-2a plus ribavirin therapy in Korean patients with chronic hepatitis $\mathrm{C}$ in clinical practice. Clin Mol Hepatol 2013;19:60-69.

19. Jin YJ, Lee JW, Lee JI, et al. Multicenter comparison of PEG-IFN $\alpha 2 a$ or $\alpha 2 b$ plus ribavirin for treatment-naïve HCV patient in Korean population. BMC Gastroenterol 2013;13:74.

20. Kang MJ, Jung EU, Park SW, et al. Effects of pegylated interferon and ribavirin in Korean patients with chronic hepatitis C virus infection. Korean J Hepatol 2008;14:318330.

21. Lyoo K, Song MJ, Hur W, et al. Polymorphism near the IL28B gene in Korean hepatitis C virus-infected patients treated with peg-interferon plus ribavirin. J Clin Virol 2011;52:363-366.

22. Yu ML, Huang CF, Huang JF, et al. Role of interleukin-28B polymorphisms in the treatment of hepatitis C virus genotype 2 infection in Asian patients. Hepatology 2011;53:7-13.

23. Lo Re V 3rd, Teal V, Localio AR, Amorosa VK, Kaplan DE, Gross R. Relationship between adherence to hepatitis C virus therapy and virologic outcomes: a cohort study. Ann Intern Med 2011;155:353-360.

24. Yu JW, Wang GQ, Sun LJ, Li XG, Li SC. Predictive value of rapid virological response and early virological response on sustained virological response in HCV patients treated with pegylated interferon alpha-2a and ribavirin. J Gastroenterol Hepatol 2007;22:832-836.
25. Shirakawa H, Matsumoto A, Joshita S, et al. Pretreatment prediction of virological response to peginterferon plus ribavirin therapy in chronic hepatitis $\mathrm{C}$ patients using viral and host factors. Hepatology 2008;48:1753-1760.

26. Davis GL, Wong JB, McHutchison JG, Manns MP, Harvey J, Albrecht J. Early virologic response to treatment with peginterferon alfa-2b plus ribavirin in patients with chronic hepatitis C. Hepatology 2003;38:645-652.

27. Osada M, Kaneko M, Sakamoto M, et al. Causes of thrombocytopenia in chronic hepatitis $\mathrm{C}$ viral infection. Clin Appl Thromb Hemost 2012;18:272-280.

28. Ferenci P. Predictors of response to therapy for chronic hepatitis C. Semin Liver Dis 2004;24 Suppl 2:25-31.

29. Kauf TL, Nelson DR, Schelfhout J, Delaney JA, Wang PF. Trends in the prevalence of thrombocytopenia among individuals infected with hepatitis C virus in the United States, 1999-2008. BMC Res Notes 2012;5:142.

30. Lee HS, Kim JK, Cheong JY, et al. Prediction of compensated liver cirrhosis by ultrasonography and routine blood tests in patients with chronic viral hepatitis. Korean J Hepatol 2010;16:369-375.

31. Kurosaki M, Sakamoto N, Iwasaki M, et al. Pretreatment prediction of response to peginterferon plus ribavirin therapy in genotype 1 chronic hepatitis $\mathrm{C}$ using data mining analysis. J Gastroenterol 2011;46:401-409.

32. Kim SR, El-Shamy A, Imoto S, et al. Prediction of response to pegylated interferon/ribavirin combination therapy for chronic hepatitis $\mathrm{C}$ genotype $\mathrm{ib}$ and high viral load. J Gastroenterol 2012;47:1143-1151.

33. Kanda T, Kato K, Tsubota A, et al. Platelet count and sustained virological response in hepatitis $\mathrm{C}$ treatment. World J Hepatol 2013;5:182-188. 